\title{
POTENCIALIDADES DO SISTEMA ARCU-SUL PARA A CONSTRUÇÃO DO MODELO REGIONAL DE RECONHECIMENTO DE TÍTULOS
}

\author{
MARIANNE PEREIRA DE SOUZA $1 ; *$ \\ ORCID: https://orcid.org/0000-0002-5502-8073 \\ GISELLE CRISTINA MARTINS REAL $2 ; * *$ \\ ORCID: http://orcid.org/0000-0002-88554141
}

\begin{abstract}
RESUMO: O presente trabalho tem como objetivo investigar as potencialidades da política regional de avaliação, configurada no Sistema de Acreditação de Cursos Universitários do Mercosul, para a construção de um modelo de reconhecimento de títulos. Metodologicamente, trata-se de uma pesquisa documental. Em que pesem indefinições acerca de questões importantes para a implementação da política regional, os dados evidenciam que os Estados Partes progrediram na construção de um mecanismo permanente de reconhecimento de títulos. Em síntese, o Sistema regional constitui uma estratégia de indução eficiente, uma vez que relaciona os resultados da acreditação com a regulação de diplomas. Desse modo, o Sistema do Mercosul possui potencial para determinar qualidade na educação superior e, consequentemente, induzir o reconhecimento de títulos nos países, a partir de um modelo regional.
\end{abstract}

Palavras-chave: Mercosul, Qualidade Educacional, Acreditação, Regulação

\section{POTENTIALITIES OF THE ARCU-SUL SYSTEM FOR THE CONSTRUCTION OF A REGIONAL MODEL OF DEGREE RECOGNITION}

\begin{abstract}
This work aims to investigate the potentialities of the regional evaluation policy, configured in the Accreditation System for University Courses of Mercosul, to build a model for recognition of degrees. Methodologically, this is a documentary research. Unconcerned of uncertainties about issues that are important for the implementation of regional policy, the data show that States Parties have made progress in building a permanent mechanism for the recognition of diplomas. In short, the Regional System is an efficient induction strategy, since it relates the results of accreditation with the regulation of diplomas. Accordingly, the system of Mercosul has the potential to determine quality in higher education and, consequently, to induce the recognition of degrees in the countries, based on a regional model.
\end{abstract}

Keywords: Mercosul, Educational Quality, Accreditation, Regulation

\section{POTENCIALES DEL SISTEMA ARCU-SUR PARA LA CONSTRUCCIÓN DEL MODELO REGIONAL DE RECONOCIMIENTO DE TÍTULOS}

\footnotetext{
${ }^{1}$ Universidade Estadual de Mato Grosso do Sul. Dourados, MS, Brasil.

* Doutora em Educação. <mariannesouza@uems.br>

${ }^{2}$ Universidade Federal da Grande Dourados. Dourados, MS, Brasil.

** Doutora em Educação. <gcreal@terra.com.br>
} 
RESÚMEN: El trabajo tiene como objetivo investigar el potencial de la política de evaluación regional, configurada en el Sistema de Acreditación Regional de Carreras Universitarias del Mercosur, para la construcción de un modelo de reconocimiento de títulos. Metodológicamente, es una investigación documental. A pesar de la incertidumbre sobre cuestiones importantes para la implementación de la política regional, los datos muestran que los Estados Partes han avanzado en la construcción de un mecanismo permanente para el reconocimiento de títulos. En resumen, el Sistema Regional constituye una estrategia de inducción eficiente, ya que vincula los resultados de la acreditación con la regulación de los diplomas. De esta manera, el Sistema del Mercosur tiene el potencial de determinar la calidad en la educación superior y, en consecuencia, inducir el reconocimiento de títulos en los países, en base a un modelo regional.

Palabras clave: Mercosur, Calidad educativa, Acreditación, Regulación

\section{INTRODUÇÃO}

Nas últimas décadas, devido ao valor econômico dos diplomas de graduação e de sua importância para o processo de integração regional, os blocos econômicos, dentre os quais o Mercado Comum do Sul (Mercosul), intensificaram a promoção de normas e procedimentos regulamentadores para a educação superior. Dentre os procedimentos constantes na agenda do Mercosul figura o reconhecimento dos diplomas obtidos no exterior, uma das preocupações dos sistemas educacionais dos países latino-americanos (LAMARRA, 2010; REAL, 2011).

Nesse sentido, com o objetivo de facilitar a movimentação de pessoas entre os países da região e servir como apoio para os mecanismos regionais de reconhecimento de títulos ou diplomas universitários, os países integrantes do Mercosul instituíram o Sistema de Acreditação de Cursos Universitários do Mercosul (ARCU-SUL ${ }^{3}$ ).

A partir de 2008, foram realizados diversos estudos ${ }^{4}$ que tratam do ARCU-SUL, uma vez que o primeiro ciclo de implementação ocorreu entre os anos de 2008 e 2015. Parte desses estudos aponta avanços da política regional de acreditação para garantia de qualidade (SCHMOELLER et al, 2012) e para melhoria da qualidade da educação superior (GRIBOSKI; FUNGHETTO, 2016). Nesse sentido, Barreyro, Hizume e Lagoria (2015) consideram que o ARCU-SUL está atingindo os objetivos que foram propostos. Contudo, outros autores explicitam limitações do Sistema, especialmente nas concepções diversificadas sobre a acreditação de cursos (VERHINE; FREITAS, 2012; REAL; OLIVEIRA, 2016; SOUZA, 2016), na operacionalização do processo realizado pelas agências nacionais de acreditação (HIZUME, 2013; MIORANDO, 2014; SERIKAWA, 2013) e nos efeitos limitados da acreditação (MIORANDO, 2014), uma vez que não há um acordo entre os governantes sobre quais serão as implicações do carimbo de qualidade a ser conferido (VERHINE; FREITAS, 2012), e o reconhecimento de títulos é motivo de resistências, especialmente por parte do Brasil (KRAWCZYK; SANDOVAL, 2012).

O conjunto dos trabalhos supracitados aponta, em certa medida, avanços e fragilidades do ARCU-SUL. Contudo, a análise das produções também mostrou as lacunas que permeiam a literatura da área, especialmente no que concerne à relação da acreditação regional com o reconhecimento de títulos nos países do Mercosul.

\footnotetext{
${ }^{3}$ O ARCU-SUL foi instituído por meio do Acordo n 17/2018, assinado em San Miguel de Tucumán, na República Argentina, em junho de 2008, e homologado pela Decisão CMC n ${ }^{\circ}$ 17/2008. Registra-se que, na tradução do referido acordo para a língua portuguesa, a palavra em espanhol acreditación foi traduzida como credenciamento. No entanto, para o presente trabalho optou-se pela palavra acreditação, respaldado na informação do MEC sobre o seu uso nas políticas do Mercosul (BRASIL, 2014).

${ }^{4}$ A pesquisa bibliográfica contou com buscas por dissertações de mestrado e teses de doutorado (2000-2016); resultados de pesquisas publicados em artigos científicos de periódicos nacionais e internacionais; trabalhos nas reuniões da Associação Nacional de Pós-Graduação e Pesquisa em Educação (ANPEd) e livros brasileiros. Foram encontrados 18 trabalhos que abordam o ARCU-SUL.
} 
Diante das lacunas encontradas na literatura, o presente trabalho tem como objetivo investigar as potencialidades da política regional de avaliação, configurada no Sistema ARCU-SUL, para a construção de um modelo de reconhecimento de títulos de graduação.

Metodologicamente, trata-se de uma pesquisa documental. O corpus compreende documentos do Setor Educacional do Mercosul (SEM) que abordam, especialmente, a educação superior.

O referencial teórico de análise parte do entendimento da regionalização, ainda que simultaneamente a um movimento de integração de Estados-nação, como uma necessidade da globalização (IANNI, 2004). Para o mesmo autor, "o regionalismo envolve a formação de sistemas econômicos que redesenham e integram economias nacionais, preparando-as para os impactos e as exigências ou as mudanças e os dinamismos do globalismo" (IANNI, 2004, p. 101).

Assim, como a política regional é formulada e implementada na interseção das demandas do bloco econômico para a educação superior e a autonomia dos sistemas nacionais, as análises realizadas neste trabalho estão respaldadas nos estudos de Dale (2009) que, considerando a globalização e seus efeitos para a educação, propõe a existência de modelos regionais de educação.

Conforme o mesmo autor, com o crescimento dos modelos regionais de educação, que apresentam diferenças importantes em relação aos modelos nacionais, a construção do regionalismo passou então a ser representada como um dos principais problemas enfrentados pelos Estados-nação. E, diante da importância do regionalismo em educação, ocorreram mudanças em relação à governança e ao papel do Estado-nação nas políticas educacionais.

O trabalho está dividido em três seções, além da introdução e das considerações finais. A primeira seção enfoca a relação da acreditação com o reconhecimento de títulos no âmbito do Mercosul; a segunda apresenta o movimento de construção do modelo regional de reconhecimento de títulos; e, na última, o foco recai sobre as potencialidades do ARCU-SUL para vincular a acreditação regional com a regulação.

\section{RELAÇÃO DA ACREDITAÇÃO COM O RECONHECIMENTO DE TÍTULOS NO ÂMBITO DO MERCOSUL}

O reconhecimento de títulos de graduação nos países latino-americanos é um dos assuntos debatidos com maior frequência nas reuniões do Setor Educacional do Mercosul (SEM) e permeia os protocolos de integração, planos de ação e outros documentos elaborados para a educação superior.

As primeiras ações do SEM visaram apenas ao reconhecimento de títulos para as atividades acadêmicas. Nessa direção, em 1996, foi elaborado o Protocolo de Integração Educacional para Prosseguimento de Estudos de Pós-Graduação nas Universidades dos Estados Partes do Mercosul, aprovado por meio da Decisão CMC no 08/1996, de 17 de dezembro, bem como o Acordo de Admissão de Títulos e Graus Universitários para o Exercício de Atividades Acadêmicas nos Estados Partes do Mercosul, aprovado por meio da Decisão CMC no 04/99, de 15 de junho de 1999.

Concomitante à aprovação do acordo, a questão do reconhecimento de títulos foi inserida nos planos trienais e de ação elaborados pelo SEM para a educação. Para fundamentar as decisões nacionais acerca do reconhecimento de títulos, os países do Mercosul passaram a discutir a adoção de um sistema regional de acreditação de cursos.

Cabe destacar que a acreditação é um fenômeno complexo (KNIGHT, 2006) que pode desempenhar papéis diversos, que envolvem desde a melhoria da qualidade dos sistemas educacionais até a sua regulação. E como a avaliação, a partir de processos sistêmicos, é a principal estratégia das políticas educacionais que buscam qualidade, a acreditação de cursos é realizada em grande parte dos sistemas a partir dos resultados da autoavaliação e da avaliação externa (DIAS SOBRINHO, 2011; VERHINE; FREITAS, 2012).

Desse modo, no âmbito do Mercosul, a acreditação diz respeito ao processo de certificação da qualidade dos cursos, que é apresentada como uma ferramenta importante para a movimentação de pessoas na região e, consequentemente, para a melhoria das condições de empregabilidade. Ou seja, a acreditação regional é utilizada para induzir o reconhecimento dos títulos emitidos pelos países integrantes do bloco. 
Nesse sentido, a avaliação e a acreditação foram elencadas no Plano Trienal do período 19982000, que contou com metas direcionadas à implementação do mecanismo experimental de acreditação de cursos para o reconhecimento de títulos de graduação universitária nos países do Mercosul. Ressaltase que essas metas foram reafirmadas no Plano Estratégico 2001-2005.

Contudo, a criação do Mecanismo Experimental de Acreditação de Cursos para o Reconhecimento de Títulos de Graduação Universitária nos Países do Mercosul (Mexa) ocorreu somente em 1998, e a implementação, entre os anos de 2004 e 2006. O Mexa acreditou um total de 68 cursos, distribuídos nas titulações de agronomia, engenharia e medicina (MERCOSUL, 2016a).

Mesmo considerado positivo pelos ministros de educação dos países do Mercosul (MERCOSUL, 2008; 2016a) e por autores como Stubrin (2005), o mecanismo não foi suficiente para o avanço dos acordos sobre o reconhecimento de títulos (SOLANAS, 2014). Segundo Solanas (2014), o reconhecimento de títulos previsto a partir do Mexa teria validade somente para fins acadêmicos, e não para o exercício profissional nos países da região, decisão que gerou diversos conflitos.

Assim, o Plano de Ação 2006-2010 definiu como um dos objetivos para o período a adoção de um mecanismo permanente de acreditação, considerando os resultados do mecanismo experimental (MERCOSUL, 2006), o que ocorreu em 2008, com a criação do ARCU-SUL. E no Sistema, diferentemente do que estava previsto no Mexa, o reconhecimento de títulos ou diplomas de grau universitário não teria validade apenas para as atividades acadêmicas, mas também para o exercício profissional nos países da região.

A esse respeito, a literatura (ROBLEDO; CAILLÓN, 2009; SOLANAS, 2014) aponta que o ARCU-SUL, na qualidade de sistema permanente, possui potencialidades, e, ao longo de sua implementação, o SEM conseguiria apresentar avanços em relação ao reconhecimento para o exercício profissional.

O Plano de Ação do SEM 2011-2015 reafirmou a necessidade de políticas para a melhoria da qualidade, por meio de objetivos específicos, ações e metas convergentes em torno do fortalecimento do Sistema de Acreditação (MERCOSUL, 2011). Dentre as metas do referido Plano, constam: o fortalecimento do ARCU-SUL, a consolidação e o aprofundamento do ARCU-SUL envolvendo um maior número de IES e de carreiras com o objetivo de melhoria da qualidade e o reconhecimento de títulos, e a avaliação do Sistema ARCU-SUL com vistas à sua própria expansão e diversificação.

Verifica-se que a acreditação de cursos foi formulada considerando a melhoria da qualidade, mas com uma perspectiva regulatória, uma vez que sua implementação tem como finalidade o mecanismo para o reconhecimento de títulos nos países da região. A perspectiva regulatória da acreditação está presente tanto nos blocos temáticos/linhas programáticas, como nos objetivos/metas dos planos do SEM elaborados para os anos de 1998 a 2015.

Nessa mesma direção, o Plano de Ação vigente para o período 2016-2020 prevê, como uma das atividades específicas da Comissão Regional Coordenadora de Educação Superior (CRC-ES), a aprovação de um acordo de reconhecimento de títulos com base na acreditação regional que permita validar os títulos em sua totalidade, tanto nos âmbitos acadêmicos como nos profissionais.

Desse modo, é possível verificar a importância da acreditação na política regional. Dentre os motivos que levaram o SEM a valorizar esse processo, podem-se elencar a cultura da avaliação nas políticas dos países do Mercosul e a necessidade de garantir qualidade educacional para atrair a mobilidade entre os países.

Em relação à avaliação, destaca-se que, na maior parte dos países do Mercosul, os sistemas foram instituídos como consequência da expansão da educação superior, entre os anos 1990 e os anos 2000. A literatura explicita que, nesse período, houve a consolidação de agências para avaliação e/ou acreditação da educação superior no âmbito nacional, que em alguns contextos desempenham tanto a função de certificação da qualidade como de regulação dos sistemas (LAMARRA, 2012; LEITE; GENRO, 2012; PIRES; LEMAITRE, 2008; RAMA, 2009; VERHINE; FREITAS, 2012).

Assim, embora a acreditação ocorra impulsionada pela necessidade de convergência das políticas de educação superior na região (LAMARRA, 2010), os sistemas foram engendrados considerando-se as particularidades nacionais, uma vez que a recepção das agendas avaliativas não é indiferente às especificidades dos diferentes países (AFONSO, 2013). Desse modo, não é possível afirmar sobre uma definição convergente acerca do conceito de acreditação de cursos. 
O documento que instituiu o ARCU-SUL define que a acreditação é resultado do processo de avaliação "[...] por meio do qual é certificada a qualidade acadêmica dos cursos de graduação estabelecendo que satisfazem o perfil do graduado e os critérios de qualidade previamente aprovados no âmbito regional para cada diploma" (MERCOSUL, 2008, p. 3).

Dessa forma, no Mercosul, a acreditação legitima os resultados da avaliação, realizada a partir de um perfil determinado para o graduado e de critérios considerados representativos da qualidade regional.

Contudo, acredita-se que o reconhecimento mútuo de títulos seria o mote da avaliação, uma vez que é a finalidade do processo de acreditação de cursos em âmbito regional. Isso porque, conforme o Acordo no 17/2018, o processo de acreditação no ARCU-SUL será incentivado

[...] como critério comum para facilitar o reconhecimento mútuo de títulos ou diplomas de grau universitário para o exercício profissional em convênios ou tratados ou acordos bilaterais, multilaterais, regionais ou sub-regionais que venham a ser celebrados a esse respeito (MERCOSUL, 2008, p. 6).

Percebe-se que a acreditação foi instituída como referencial para o reconhecimento de títulos, ou seja, os seus resultados devem ser utilizados para finalidades e efeitos regulatórios ${ }^{5}$. Dessa forma, verificam-se interfaces da acreditação realizada em âmbito regional com a regulação efetivada nos sistemas nacionais, já que a função de fixar normas acerca do reconhecimento de títulos é dos estados nacionais, tanto no que diz respeito à continuidade dos estudos, como no que se refere ao exercício profissional.

No primeiro ${ }^{6}$ ciclo do Sistema, que é gerenciado pela Rede de Agências Nacionais de Acreditação (Rana), foram acreditados 246 cursos oriundos da Argentina, Bolívia, Brasil, Chile, Colômbia, Paraguai, Uruguai e Venezuela. Cabe dizer que o processo de acreditação foi destinado às seguintes titulações: agronomia, arquitetura, enfermagem, engenharia, medicina, medicina veterinária e odontologia.

Diante da implementação do primeiro ciclo, o SEM trabalhou para articular os resultados da acreditação com o reconhecimento de títulos nos países integrantes do bloco econômico, tópico abordado a seguir.

\section{MOVIMENTO DE CONSTRUÇÃO DO MODELO REGIONAL DE RECONHECIMENTO DE TÍTULOS}

Com o objetivo de viabilizar um mecanismo de reconhecimento de títulos a partir dos resultados do ARCU-SUL, o SEM criou o Grupo de Trabalho para o Reconhecimento de Títulos de Graduação do Mercosul (GT-RT), que é composto por delegações da Argentina, Brasil, Paraguai e Uruguai.

As reuniões do GT-RT foram realizadas a partir de 2010, quando os países participantes acordaram na proposta de Plano de Trabalho. De acordo com o documento, o processo de reconhecimento de títulos no Mercosul teria as seguintes diretrizes gerais:

a. El processo estará basado en la garantia de la calidad de las carreras.

b. El processo se implementará a partir de acuerdos de reválida de títulos de las carreras acreditadas por el Sistema ARCUSUR a realizar por las universidades públicas, sujeito a un análisis específico de cada titulación.

c. El ingresso de cada institución de educación superior pública al Sistema ARCUSUR implicará el compromisso de revalidar dichos títulos.

\footnotetext{
${ }^{5}$ Para Barroso (2005), a regulação compreende a “[...] produção de regras (normas, injunções, constrangimentos etc.) que orientam o funcionamento do sistema, mas também o (re)ajustamento da diversidade de acções dos actores em função dessas mesmas regras" (BARROSO, 2005, p. 733).

${ }^{6}$ Os dados foram coletados na página eletrônica oficial do Sistema em novembro de 2015. Ressalta-se que, embora a Rana tenha previsto o início do segundo ciclo para o ano de 2015, consta na Ata de Reunião da Rana, realizada em abril de 2017, que "Brasil informa que se cerrará el primer ciclo del Sistema ARCU-SUR com la acreditación de carreras de Medicina y Odontologia em 2017” (MERCOSUL, 2017a).
} 
d. El processo de reválida no exigirá requisitos académicos adicionales (MERCOSUL, 2010).

Nota-se que, de acordo com o documento, o reconhecimento de títulos no mecanismo regional seria realizado a partir dos resultados do ARCU-SUL, por universidades públicas e sem a exigência de requisitos acadêmicos adicionais.

Além das referidas diretrizes, cabe ressaltar que o documento também aborda a questão do exercício profissional, uma vez que "[...] los aspectos relativos al ejercicio professional especificos para titulación, de manera de vincular la reválida de los títulos con la habilitación y la superación de asimetrias" (MERCOSUL, 2010).

$\mathrm{Na}$ reunião ${ }^{7}$ realizada em novembro de 2015, os integrantes do GT-RT elaboraram uma proposta consolidada intitulada Experiência Piloto para el Reconocimiento de Títulos de Educación Superior Del Sector Educativo MERCOSUR, baseada nas sugestões enviadas pelas delegações da Argentina, do Brasil, do Paraguai e do Uruguai.

As propostas foram elaboradas a partir dos seguintes aspectos: carreiras acreditadas pelo ARCU-SUL a serem consideradas no mecanismo experimental, procedimentos a serem aplicados, instituições envolvidas, critérios de seleção, requisitos, prazo para análise e vigência.

Destaca-se que, para respaldar a construção do mecanismo experimental, foi realizado um Seminário Regional de Reconhecimento de Títulos, cujas definições ressaltam que o mecanismo regional não deve ser visto como um ato regulatório, mas como uma possibilidade de integração regional, baseada em características do processo como a qualidade, a confiança e a reciprocidade (MERCOSUL, 2015). Entretanto, não é possível desconsiderar que a implementação do mecanismo regional envolve decisões nacionais que configuram a produção de normas sobre o reconhecimento de títulos, ou seja, que regulam os diplomas nos sistemas educacionais.

Consta na proposta consolidada de experiência piloto que o reconhecimento é “[...] procedimiento y al acto administrativo de aceptación por parte de un país de una credencial educativa (estúdios, un título o diploma) proveniente de otro país" (MERCOSUL, 2015).

O quadro 1 expõe as definições da proposta consolidada acerca dos principais aspectos de discussão entre os países integrantes do GT-RT.

Quadro 1. Síntese da proposta de experiência piloto para o reconhecimento de títulos de educação superior do Setor Educacional do Mercosul

\begin{tabular}{|c|c|}
\hline Aspectos & Decisões dos integrantes do GT-RT \\
\hline Alcance do processo de reconhecimento & - Efeitos acadêmicos e profissionais \\
\hline Carreiras acreditadas pelo ARCU-SUL & $\begin{array}{l}\text { - Agronomia, em consulta para o Uruguai; } \\
\text { - Agronomia e Arquitetura, em consulta para o Paraguai; e } \\
\text { - Agronomia, acompanhada no âmbito do Sinard para o Brasil }\end{array}$ \\
\hline Procedimentos a serem aplicados & $\begin{array}{l}\text { - Cada país determinará o mecanismo que utilizará, respeitando } \\
\text { a sua normativa }\end{array}$ \\
\hline \multicolumn{2}{|l|}{ Instituições envolvidas } \\
\hline Critérios de seleção & $\begin{array}{l}\text { - Cursos que já foram acreditados no ARCU-SUL pela segunda } \\
\text { vez }\end{array}$ \\
\hline Requisitos & - Não se exigiram requisitos acadêmicos adicionais \\
\hline Prazo para análise & - Até seis meses \\
\hline Vigência & $\begin{array}{l}\text { - Avaliação média em } 18 \text { meses e avaliação somativa em } 36 \\
\text { meses }\end{array}$ \\
\hline
\end{tabular}

Fonte: Elaborado a partir da Acta no 02/15, de 6 de noviembre de 2015 (MERCOSUL, 2015).

Em relação ao alcance ao reconhecimento, a proposta enfatiza que o processo teria efeitos tanto para fins acadêmicos como profissionais, conforme trecho a seguir:

\footnotetext{
${ }^{7}$ Destaca-se que a página eletrônica do SEM não disponibilizou as atas das reuniões do GT-RT realizadas no período de 2011 a 2014.
} 
El fin de reconocer un título es validarlo en su totalidad, con todos los efectos que esto conlleva tanto académicos como profesionales, respetando las excepciones en cada país. El ejercício profesional en áreas específicas dependerá de las normas establecidas en cada país (MERCOSUL, 2015).

Já para a seleção das carreiras, os integrantes do GT-RT corroboraram as definições do Seminário Regional de Reconhecimento de Títulos, ou seja, somente os cursos de agronomia para o Brasil e o Uruguai, e os cursos de agronomia e arquitetura, para o Paraguai.

Observa-se que o documento informa que, no Brasil, o mecanismo experimental será acompanhado pelo Sistema Nacional de Revalidação de Diplomas (Sinard), que estaria em construção pelo Ministério da Educação (MEC) e teria o objetivo de auxiliar as universidades em relação à revalidação (MERCOSUL, 2015). Todavia, na página eletrônica do MEC não há informações sobre o referido sistema. E, nas normatizações aprovadas em 2016, consta a criação da plataforma Carolina Bori ${ }^{8}$ para subsidiar as universidades na "[...] execução e a gestão de processos de revalidação e reconhecimento de diplomas" (BRASIL, 2016b, p. 9).

No que diz respeito aos critérios de seleção das carreiras que participarão da experiência piloto, os países aceitaram considerar somente os cursos que já foram acreditados no ARCU-SUL pela segunda vez, como se segue:

\footnotetext{
- Mayor experiencia em acreditación regional por el Sistema ARCU-SUR, se aplicará en carreras acreditadas por segunda vez y con vigência de la resolución de acreditación.

- Considerar especialmente a las disciplinas que impliquen interesses estratégicos para el desarrollo de los países y compartidos en la región (MERCOSUL, 2015).
}

E, diante do potencial da avaliação realizada pelo ARCU-SUL para garantir que os cursos possuam qualidade, os integrantes do GT-RT acordaram que não serão exigidos requisitos acadêmicos adicionais.

O prazo proposto para a finalização do reconhecimento foi de até seis meses após o início do processo. Já acerca da vigência da experiência piloto, os integrantes do GT-RT decidiram que “[...] deberá ser monitoreada por el Grupo de Trabajo y sometida a una evaluación de médio término (18 meses después del inicio) y a una evaluación somativa a los três años" (MERCOSUL, 2015).

Observa-se que os integrantes do grupo não conseguiram acordar sobre um procedimento comum que contemplaria as necessidades do mecanismo regional. Nesse sentido, cabe questionar se as decisões internas não induzirão conflitos relacionados aos objetivos e alcances da experiência piloto, uma vez que os sistemas nacionais possuem diferenças significativas como o conceito, os objetivos e os mecanismos utilizados para o reconhecimento de títulos (MERCOSUL, 2015).

Além disso, a proposta também omite as instituições a serem envolvidas no processo que, segundo as diretrizes definidas no GT-RT, seriam as universidades públicas, bem como não menciona que todas as universidades com cursos acreditados pelo ARCU-SUL deverão participar da revalidação de títulos.

Percebe-se também que ainda persistem desafios para a implementação da experiência piloto no contexto regional, como os mecanismos a serem utilizados pelos sistemas nacionais. Esses mecanismos pautaram a reunião realizada em março de 2016, no Uruguai, que contou com a presença das delegações da Argentina, do Paraguai e da Bolívia. A respeito da última delegação, vale lembrar que o Uruguai está em processo de adesão como Estado Parte, e essa foi a sua primeira participação nas reuniões do GT-RT.

Ao mesmo tempo que definiram os pontos necessários para informe, os integrantes do GTRT acordaram sobre o início da "[...] redación de un documento borrador del Acuerdo para la aprobación de la experiencia” (MERCOSUL, 2016b).

Dessa forma, decidiram os encaminhamentos futuros para a implementação do mecanismo experimental, uma vez que o cronograma desse processo foi aprovado no âmbito da CRC-ES

\footnotetext{
${ }^{8}$ Consultar: <http://plataformacarolinabori.mec.gov.br/usuario/acesso>. Acesso em 10 out. 2017.
} Educação em Revista|Belo Horizonte|v.36|e216226|2020 
(MERCOSUL, 2016b). No entanto, a página eletrônica do SEM não disponibilizou as atas das demais reuniões realizadas em 2016.

O único documento ${ }^{9}$ encontrado sobre as reuniões posteriores trata da reunião do GT-RT e da Reunião Conjunta com a CRC-ES, da qual participaram Argentina, Bolívia, Paraguai e Uruguai. Nessa reunião, a Argentina apresentou uma proposta de acordo de reconhecimento de títulos do Mercosul.

O documento apresentado pela Argentina propõe um acordo de reconhecimento de títulos e diplomas de educação superior universitária entre os Estados Partes do Mercosul. Considerando o seu título, entende-se que a proposta diz respeito a um acordo permanente entre os Estados Partes, diferentemente da proposta exposta anteriormente.

Conforme o documento de trabalho, o acordo de reconhecimento estaria estruturado em oito artigos, cujos aspectos principais estão sintetizados no quadro 2. Cabe mencionar que a análise do documento partiu dos aspectos utilizados para a avaliação da proposta de experiência piloto explicitados no quadro 1.

Quadro 2. Síntese da proposta de acordo de reconhecimento de títulos e diplomas de educação superior entre os Estados Partes do Mercosul

\begin{tabular}{|c|l|}
\hline \multicolumn{1}{|c|}{ Aspectos } & \multicolumn{1}{|c|}{ Decisões dos integrantes do GT-RT } \\
\hline Alcance do processo de reconhecimento & $\begin{array}{l}\text { - O reconhecimento produzirá os efeitos que cada Estado Parte } \\
\text { confere aos seus próprios títulos e diplomas oficiais }\end{array}$ \\
\hline Carreiras acreditadas pelo ARCU-SUL & \\
\hline Procedimentos a serem aplicados & $\begin{array}{l}- \text { Para a aplicação do Acordo e solução de controvérsias será } \\
\text { constituído um Grupo de Trabalho }\end{array}$ \\
\hline Instituições envolvidas & $\begin{array}{l}\text { - Títulos e diplomas com acreditação vigente no ARCU-SUL no } \\
\text { momento da emissão do título }\end{array}$ \\
\hline Critérios de seleção & - Não serão exigidos requisitos acadêmicos adicionais \\
\hline Requisitos & \\
\hline Prazo para análise & - Indefinida \\
\hline Vigência & \\
\hline
\end{tabular}

Fonte: Elaborado a partir da Acta n ${ }^{\circ}$ 01/17, de 18 de abril de 2017 (MERCOSUL, 2017b).

Pode-se constatar nos dados do quadro 2 que a proposta de acordo apresenta semelhanças e diferenças quanto à proposta da experiência piloto, as quais serão discutidas a seguir.

Dentre as semelhanças dos documentos, está a ausência de requisitos acadêmicos adicionais. Conforme o artigo $4^{\circ}$ da proposta, "no obstante lo anterior, y para assegurar un trato no discriminatorio, dichas normas no pódran exigir en ningún caso requisitos adicionales a los titulados en instituciones de las otras Partes que a los titulados en la propias" (MERCOSUL, 2017b).

A proposta de acordo também não define quais serão as instituições envolvidas no processo, mas consta no artigo $6^{\circ}$ que, para todos os efeitos da implementação do documento, será constituído um grupo de trabalho no marco da CRC-ES, e as controvérsias que surjam entre os Estados Partes serão resolvidas mediante negociações diplomáticas diretas.

Já em relação aos efeitos do reconhecimento, a proposta de acordo é menos específica do que a proposta anterior, a qual definia que tais efeitos seriam acadêmicos e profissionais. De acordo com o artigo $4^{\circ}$ do acordo, o reconhecimento produzirá os efeitos que cada Estado Parte confere aos seus próprios títulos e diplomas oficiais. E, "[...] para aquellos títulos y diplomas vinculados al ejercicio de profesiones reguladas será necessário cumplir con los requisitos no académicos que cada Parte exige, de acuerdo a las normas legales vigentes para cada profesion” (MERCOSUL, 2017b).

Desse modo, o documento garante o exercício profissional aos portadores de diplomas estrangeiros reconhecidos nos Estados Partes, desde que cumpridos os requisitos não acadêmicos exigidos em âmbito nacional, o que estaria contemplando as normativas das instituições corporativas para a atuação profissional.

\footnotetext{
9 Nessa direção, consultar: <http://www.edu.mercosur.int/pt-BR/atas-de-reunioes-do-setor-educacional-do-mercosulcmc/viewcategory/1372-2017.html>. Acesso em 01 ago. 2017. 
Outra diferença diz respeito às carreiras acreditadas pelo ARCU-SUL que participarão do processo. Verifica-se que o documento, ao contrário da proposta de experiência piloto, não menciona os cursos de agronomia e arquitetura, ou seja, entende-se que todas as carreiras acreditadas pelo Sistema poderão participar.

Nessa direção, o documento também define que todos os cursos com acreditação vigente no ARCU-SUL terão seus títulos reconhecidos nos Estados Partes, o que contraria a proposta anterior, segundo a qual participariam somente os cursos acreditados no Sistema pela segunda vez.

Por outro lado, ao explicitarem que o documento terá duração indefinida, os elaboradores da proposta evidenciam novamente o caráter permanente do acordo de reconhecimento de títulos entre os Estados Partes do Mercosul.

O documento não trata de especificidades da implementação do acordo, como os mecanismos utilizados nos sistemas nacionais e o prazo para a divulgação dos resultados. Compreendese, então, que essas questões serão debatidas no âmbito do GT-RT, o que já ocorre desde 2015.

Essas constatações suscitam o seguinte questionamento: quais são os fatores que tornam os processos de elaboração e de implementação do mecanismo regional de reconhecimento de títulos tão moroso?

Entende-se como uma possível resposta que o movimento de construção do mecanismo regional é permeado por tensões e contradições que envolvem tanto aspectos técnicos como aspectos políticos que perfazem a política regional para a educação superior.

Como exemplo das contradições geradas no interior do bloco, pode-se destacar o trabalho acerca da elaboração de uma experiência piloto que, de acordo com as definições do Seminário Regional, seria necessária para aperfeiçoar os mecanismos de cada país e monitorar o processo.

Contudo, os integrantes do GT-RT desistiram da construção de um mecanismo experimental e passaram a propor um acordo de implementação do mecanismo regional permanente, conforme previsto no Plano de Ação vigente para o SEM. Uma possível justificativa para as mudanças no planejamento regional são as alterações engendradas nas normatizações nacionais.

Dentre as alterações nacionais, importa ressaltar o caso do Brasil, que mostrou resistências ao reconhecimento automático de títulos estrangeiros, mas que participa do GT-RT desde sua criação, indicando inclusive propostas para a criação do mecanismo regional.

A resistência brasileira é um dos pontos de tensão da implementação do ARCU-SUL. Nesse sentido, Verhine e Freitas (2012, p. 23-24) afirmam que, para alguns países, dentre os quais o Brasil, a acreditação é entendida como "[...] chancela de qualidade, mas não tem a força de regulação, o que significa que o reconhecimento de títulos deve ser realizado de acordo com procedimentos estabelecidos internamente, no âmbito de cada país".

Dentre as inferências sobre outros motivos que levariam o país a resistir contra o reconhecimento automático de títulos oriundos de cursos acreditados pelo ARCU-SUL, destacam-se os efeitos da educação transfronteira ${ }^{10}$ (KNIGHT, 2006), que ocorre nos países vizinhos ao Brasil, como Bolívia e Paraguai, e apresenta impactos para o sistema brasileiro, dentre os quais o reconhecimento de títulos. Ademais, o ARCU-SUL não avalia o desempenho dos estudantes, considerado elemento-chave para a garantia de qualidade no sistema brasileiro.

Entretanto, os motivos da resistência não foram suficientes para impedir mudanças na normativa nacional, já que o Estado brasileiro instituiu a revalidação de títulos simplificada para os cursos acreditados pelo ARCU-SUL. Isso significa que, embora não tenha aprovado a revalidação automática, o executivo dispensou os referidos cursos de uma análise mais aprofundada ou processo de avaliação específico. E como os resultados do ARCU-SUL estão qualificados para o reconhecimento de títulos, ele assim consegue reunir justificativas para convencer os atores nacionais a acolherem a política regional de acreditação.

Segundo a normatização brasileira, aprovada em 2016, a tramitação simplificada deverá se ater, exclusivamente, à verificação da documentação comprobatória da diplomação no curso e não poderá realizar processos avaliativos específicos (BRASIL, 2016a; 2016b). Ou seja, embora não tenha aprovado

\footnotetext{
${ }^{10}$ De acordo com Knight (2006), na faixa de fronteira, há um movimento de migração de conteúdos, materiais e de pessoas, o qual é identificado como crossborder education. 
a revalidação automática, o executivo dispensou os referidos cursos de uma análise mais aprofundada ou processo de avaliação específico.

Portanto, antes de o Conselho Nacional de Educação emitir a Resolução nº 3/2016, os representantes do governo brasileiro no Mercosul já sinalizavam suas intenções quanto ao reconhecimento para os cursos acreditados pelo ARCU-SUL. Ressalta-se que a revalidação simplificada também consta no projeto de lei que tramita no âmbito do legislativo brasileiro desde 2011.

Desse modo, pode-se inferir que o Brasil regulamentou a revalidação simplificada de forma congruente com as demandas do Setor Educacional do Mercosul. Nesse sentido, Real, Marran e Zeni (2017, p. 12) afirmam que o Estado brasileiro "[...] age vigorosamente, em favor da demanda interna crescente e das políticas supranacionais que devem preponderar frente aos aspectos e valores internos das instituições universitárias (REAL; MARRAN; ZENI, 2017, p. 12).

Além disso, a Argentina e a Bolívia já possuem um convênio que garante a utilização dos resultados da acreditação regional para o reconhecimento de títulos oriundos dos dois países, assinado em 2012 e aprovado na Argentina por meio da Ley no 26869, de 5 de junio de 2013. Ou seja, diante da vinculação da acreditação regional com o reconhecimento em países como o Brasil e a Argentina, considerados lideranças no âmbito do SEM (SERIKAWA, 2013), os propósitos reservados para a experiência piloto seriam desnecessários.

Dessa forma, em que pesem indefinições acerca de questões importantes para a implementação da política regional, os Estados Partes progrediram na construção de um mecanismo permanente de reconhecimento de títulos. Consequentemente, a assinatura do acordo para vincular oficialmente o Sistema de acreditação ao reconhecimento, visando ao exercício profissional nos países da região, contribuirá para a integração dos países do Mercosul.

\section{RELAÇÃO DO ARCU-SUL COM A REGULAÇÃO: POTENCIALIDADES DA AVALIAÇÃO}

Ainda que a literatura educacional (BARREYRO; LAGORIA; HIZUME, 2015; KRAWCZYK; SANDOVAL, 2012; VERHINE; FREITAS, 2012) aponte indefinições sobre o conceito de acreditação de cursos, as ações do Mercosul para articular a acreditação regional com o reconhecimento de títulos evidenciam que o processo de regionalização busca utilizar os resultados da avaliação como ferramenta de controle dos diplomas nos sistemas nacionais.

Para tanto, com o objetivo de certificar a qualidade dos cursos de graduação, mas com a finalidade de facilitar o reconhecimento dos títulos, o ARCU-SUL adquiriu centralidade nos planejamentos do SEM. Desse modo, o discurso da qualidade foi utilizado para influenciar mudanças regulatórias nos sistemas nacionais.

Mesmo com a intensificação de ações para vincular a acreditação de cursos com o reconhecimento, o SEM não conseguiu atender às metas do Plano 2011-2015, uma vez que não foram encontrados registros da implementação de mecanismos de reconhecimento de títulos aprovados ao menos em três carreiras acreditadas, como previsto no documento.

Entretanto, é possível perceber potencialidades do ARCU-SUL para o atendimento dos objetivos e metas do SEM que focalizam a movimentação de pessoas na região, dentre as quais:

- a participação dos países integrantes do Mercosul e das suas instituições de educação superior, já que no primeiro ciclo foram acreditados 246 cursos de graduação;

- a participação dos Estados Partes no GT-RT, o que demonstra a intenção dos governos em avançarem no uso dos resultados do ARCU-SUL, o que já ocorria em países como a Argentina e a Bolívia;

- a elaboração de uma proposta de acordo para vincular oficialmente os resultados da acreditação regional ao reconhecimento de títulos, visando ao exercício profissional nos países da região.

Ademais, é relevante registrar que o Mercosul também utiliza o potencial do ARCU-SUL a fim de garantir a qualidade dos cursos para desenvolver ações de mobilidade na região. Nesse sentido, foi instituído o Programa de mobilidade acadêmica regional para os cursos acreditados pelo mecanismo de acreditação de cursos de graduação do Mercosul (Marca $\left.{ }^{11}\right)$.

\footnotetext{
${ }^{11}$ Consultar:< http://programamarca.siu.edu.ar/index.php>. Acesso em 18 out. 2017.
}

Educação em Revista|Belo Horizonte|v.36|e216226|2020 
Em síntese, pode-se afirmar que o ARCU-SUL, ao relacionar a acreditação com a regulação de diplomas, constituiu uma estratégia de indução eficiente. Assim, o Sistema do Mercosul possui potencial para determinar qualidade na educação superior e, consequentemente, induzir $\mathrm{o}$ reconhecimento de títulos nos países do bloco.

\section{CONSIDERAÇÕES FINAIS}

A qualidade dos cursos, a acreditação e o reconhecimento de títulos são fatores preponderantes para a consolidação do Mercosul tanto em âmbito regional, como em âmbito global. Isso porque as ações do SEM estão voltadas, especialmente, para a movimentação de pessoas e a melhoria das condições de empregabilidade.

Pode-se perceber que o Sistema ARCU-SUL ratificou a centralidade da acreditação para viabilização do reconhecimento de títulos nos países da região. Desse modo, a política regional destaca a perspectiva regulatória da avaliação, que pode ser definida como um mecanismo essencial para os processos regulatórios da educação superior. Isso ocorre porque, segundo Barroso (2006), Dale (2004) e Teodoro (2011), existem diversos tipos de regulações, que se diferem quanto às fontes, aos planos e aos escalões sob os quais os processos de regulação ocorrem.

No caso do Mercosul, pode-se inferir que o processo realizado se aproxima do que Hameiri e Jayasuriya (2011) denominam de regionalismo regulador, uma vez que a implementação da política regional requer a participação das estruturas nacionais, no caso do ARCU-SUL, das agências de acreditação e das universidades. Por outro lado, como as decisões regulatórias são prerrogativas dos Estados, seus governantes passaram a elaborar estratégias para acomodar as demandas regionais nas políticas locais.

Assim, entende-se que, ao mesmo tempo que o Sistema ARCU-SUL influencia as políticas nacionais, ele é influenciado pelos países integrantes do Mercosul, especialmente no que se refere às concepções e práticas utilizadas para a implementação da acreditação e do reconhecimento de títulos na região. Desse modo, embora a acreditação regional tenha potencial para induzir o reconhecimento de títulos, outros fatores dificultam os processos de elaboração e de implementação do mecanismo regional e que estão relacionados, especialmente, ao exercício profissional.

Destaca-se que as normativas para a atuação profissional nos países do Mercosul não estão vinculadas somente às políticas educacionais, mas envolvem grupos diversos, dentre os quais as instituições corporativas, que, por sua vez, também adotam o discurso da qualidade dos cursos para justificar as suas decisões. Assim, a mobilidade de pessoas no bloco envolve questões complexas e que não podem ser previstas ou resolvidas somente pelo ARCU-SUL.

Diante do exposto, são necessárias pesquisas que focalizem, nos sistemas nacionais, a influência de outros fatores que condicionam a elaboração e a implementação da acreditação regional, como as demandas internas para o reconhecimento de títulos. Além disso, cabem estudos que investiguem os desdobramentos da proposta de convênio regional, especialmente no que se refere ao exercício profissional nos países da região.

\section{REFERÊNCIAS}

AFONSO, Almerindo Janela. Mudanças no Estado-avaliador: comparativismo internacional e teoria da modernização revisitada. Revista Brasileira de Educação, v. 18, n. 53, p. 267-284, abr./jun. 2013.

BARREYRO, Gladys Beatriz; HIZUME, Gabriella de Camargo; LAGORIA, Silvana Lorena. Acreditação internacional da educação superior: considerações a partir da experiência latino-americana no Mercosul Educacional. In: SOUSA, José Vieira de (Org.). Expansão e avaliação da educação superior brasileira: formatos, desafios e novas configurações. 1. ed. Belo Horizonte: Fino Traço/Faculdade de Educação da Universidade de Brasília, 2015. p. 217-236. 
BARREYRO, Gladys Beatriz; LAGORIA, Silvana Lorena; HIZUME, Gabriella de Camargo. As agências nacionais de acreditação no sistema ARCU-SUL: primeiras considerações. Avaliação, Campinas, v. 20, n. 1, p. 49-72, 2015.

BARROSO, João. O estado, a educação e a regulação das políticas públicas. Educação \& Sociedade, Campinas, v. 26, n. 92, p. 725-751, out. 2005 (Número Especial 2005).

BARROSO, João. O Estado e a Educação: a regulação transnacional, a regulação nacional e a regulação local. In: _. (Org.). A regulação das políticas públicas de educação: espaços, dinâmicas e atores. Lisboa: Educa/Unidade de I\&D de Ciências da Educação, 2006. p. 43-70.

BRASIL. Ministério da Educação. Acreditação Regional de Cursos Universitários Mercosul. Notícias: Convocatórias a Acreditação. Portal do Ministério da Educação, 2014. Disponível em: <http://arcusul.mec.gov.br/index.php/pt-br/>. Acesso em: 10 dez. 2014.

BRASIL. Conselho Nacional de Educação. Resolução CNE/CES nº 3, de 22 de junho de 2016. Dispõe sobre normas referentes à revalidação de diplomas de cursos de graduação e ao reconhecimento de diplomas de pós-graduação stricto sensu (mestrado e doutorado), expedidos por estabelecimentos estrangeiros de ensino superior. Portal do Ministério da Educação, Brasília, 2016a, 8 p. Disponível em: $\quad<$ http://portal.mec.gov.br/index.php?option $=$ com_docman\&view $=$ download\&alias $=44661$ rces003-16-pdf\&category_slug=junho-2016-pdf\&Itemid=30192>. Acesso em: 08 maio 2017.

BRASIL. Ministério da Educação. Portaria Normativa no 22, de 13 de dezembro de 2016. Dispõe sobre normas e procedimentos gerais de tramitação de processos de solicitação de revalidação de diplomas de graduação estrangeiros e ao reconhecimento de diplomas de pós-graduação stricto sensu (mestrado e doutorado), expedidos por estabelecimentos estrangeiros de ensino superior. Diário Oficial da União, Brasilia, 14 dez. 2016b, Seção 1, p. 9-11.

DALE, Roger. Os diferentes papéis, propósitos e resultados dos modelos nacionais e regionais de educação. Educação \& Sociedade, Campinas, v. 30, n. 108, p. 867-890, out. 2009.

DIAS SOBRINHO, José. Qualidade e garantia da qualidade: acreditação da educação superior. In: ROTHEN, José Carlos; BARREYRO, Gladys. Avaliação da Educação: diferentes abordagens críticas. São Paulo: Xamã, 2011. p. 17-41.

GRIBOSKI, Cláudia Maffini; FUNGHETTO, Suzana Schwerz. A internacionalização como indicador de qualidade do Sinaes e do Sistema ARCU-SUL. In: CUNHA, Célio da; SOUSA, José Vieira de; SILVA, Maria Abádia da (Orgs.). Internacionalização da educação: discursos, práticas e reflexos sobre as políticas educativas. 1. ed. Belo Horizonte: Fino Traço, 2016. p. 243-261.

HAMEIRI, Shahar; JAYASURIYA, Kanishka. Regulatory regionalism and the dynamics of territorial politics: the case of the Asia-Pacific region. Political Studies, v. 59, n. 1, p. 20-37, 2011.

HIZUME, Gabriella de Camargo. A implementação do Sistema de Acreditação Regional de Cursos Universitários do Mercosul: um estudo sobre as agências nacionais de acreditação da Argentina e do Brasil. 2013. Dissertação (Mestrado em Integração da América Latina) - Universidade de São Paulo, São Paulo, 2013.

IANNI, Octavio. A era do globalismo. 8. ed. Rio de Janeiro: Civilização Brasileira, 2004.

KNIGHT, Jane. Higher education crossing borders: a guide to the implications of the General Agreement on Trade in Services (GATS) for cross-border education. Paris: Unesco, 2006. 76 p. 
KRAWCZYK, Nora; SANDOVAL, Salvador Antonio Mireles. O processo de regionalização das universidades do Mercosul: um estudo exploratório de regulação supranacional e nacional. Educação e Realidade, Porto Alegre, v. 37, n. 2, p. 647-668, 2012.

LAMARRA, Norberto Fernández. La convergencia de la educación superior em América Latina y su articulación con los espacios europeo e ibero-americano: Posibilidades y límites. Avaliação, Campinas, v. 15, n. 2, p. 9-44, jul. 2010.

LAMARRA, Norberto Fernández. Universidad y calidad en América Latina en perspectiva comparada: interrogantes y desafíos. Avaliação, Campinas, v. 17, n. 3, p. 661-688, nov. 2012.

LEITE, Denise; GENRO, Maria Elly Herz. Avaliação e internacionalização da educação superior: quo vadis América Latina? Avaliação, Campinas, v. 17, n. 3, p. 763-785, nov. 2012.

MERCOSUL. Mercado Comum do Sul. Acordo sobre a criação e implementação de um sistema de credenciamento de cursos de graduação para o reconhecimento regional da qualidade acadêmica dos respectivos diplomas no Mercosul e Estados Associados. San Miguel de Tucumán, Mercosul Educacional, 2008. Disponível em: <http://edu.mercosur.int/arcusur/index.php/pt-br/acordo-decriacao>. Acesso em: 10 set. 2014.

MERCOSUL. Mercado Comum do Sul. Acreditação Regional de Cursos Universitários MERCOSUL. Mercosul Educacional, 2016a. Disponível em: < http:/ / edu.mercosur.int/arcusur/index.php/pt-br/ > . Acesso em: 25 maio 2016.

MERCOSUL. Mercado Comum do Sul. Reunión de La Red de Agencias Nacionales de Acreditación. Acta $\mathbf{n}^{\mathbf{0}}$ 1/2017, de 20 de abril de 2017. Buenos Aires, 2017a. Disponível em: $<$ http://www.edu.mercosur.int/pt-BR/documentos-categoria/viewcategory/1367-2017.html>. Acesso em: 30 ago. 2017.

MERCOSUL. Mercado Comum do Sul. Reunión del Grupo de Trabajo para el Reconocimiento de Títulos de Grado del MERCOSUR. Acta n 01/10, de 13 e 14 de maio de 2010. Buenos Aires, 2010. Disponível em: <http://www.edu.mercosur.int/pt-BR/atas-de-reunioes-do-setor-educacional-domercosul-cmc/viewcategory/1349-2010.html>. Acesso em: 18 abr. 2017.

MERCOSUL. Mercado Comum do Sul. Reunión del Grupo de Trabajo para el Reconocimiento de Títulos de Educación Superior. Acta n⿳0 02/15, de 6 de noviembre de 2015. Asunción, 2015. Disponível em: $\quad<$ http://www.edu.mercosur.int/pt-BR/atas-de-reunioes-do-setor-educacional-do-mercosulcmc/viewcategory/1350-2015.html>. Acesso em: 18 abr. 2017.

MERCOSUL. Mercado Comum do Sul. Reunión del Grupo de Trabajo para el Reconocimiento de Títulos de Educación Superior. Acta n $\mathbf{n}^{\mathbf{0}}$ 01/16, de 14 e 15 de marzo de 2016. Montevideo, 2016b. Disponível em: <http://www.edu.mercosur.int/pt-BR/atas-de-reunioes-do-setor-educacional-domercosul-cmc/viewcategory/1351-2016.html>. Acesso em: 18 abr. 2017.

MERCOSUL. Mercado Comum do Sul. Reunión del Grupo de Trabajo para el Reconocimiento de Títulos. Acta $\mathbf{n}^{\mathbf{o}}$ 01/17, de 18 de abril de 2017. Buenos Aires, 2017b. Disponível em: $<$ http://www.edu.mercosur.int/pt-BR/atas-de-reunioes-do-setor-educacional-do-mercosulcmc/viewcategory/1372-2017.html>. Acesso em: 01 ago. 2017.

MERCOSUL. Mercado Comum do Sul. Setor Educacional do Mercosul. Plano de ação do Setor Educacional do Mercosul 2011- 2015. [S.l.]: SEM, 2011, 80 p. Disponível em: <http://www.edu.mercosur.int/pt-BR/plano-2011-2015.html>. Acesso em: 4 nov. 2014. 
MERCOSUL. Mercado Comum do Sul. Setor Educacional do Mercosul. Plan del Sector Educativo del Mercosur 2006-2010. [S.1.]: SEM, 2006, 48 p. Disponível em: $<$ http://www.edu.mercosur.int/ptBR/tratados/finish/7-planos-planes/412-plano-2006-2010.html>. Acesso em: 10 jun. 2017.

MIORANDO, Bernardo Sfredo. O sistema ARCU-SUL e a UFRGS: perspectiva de acreditação internacional para uma universidade latino-americana. 2014. Dissertação (Mestrado em Educação) Universidade Federal do Rio Grande do Sul, Porto Alegre, 2014.

PIRES, Sueli; LEMAITRE, Maria José. Sistemas de acreditación y evaluación de la educación superior en América Latina y el Caribe. In: GAZZOLA, Ana Lúcia; DIDRIKSSON, Axel (Eds.). Tendencias de la educación superior en América Latina y el Caribe. Caracas: Iesalc-Unesco, 2008. p. 299-318.

RAMA, Claudio. El nacimiento de la acreditación internacional. Avaliação, Campinas, v. 14, n. 2, p. 291 311, jul. 2009.

REAL. Giselle Cristina Martins. Transformações recentes na educação superior na fronteira entre Brasil e Paraguai: os anos 2000. In: LIMA, Paulo Gomes; FURTADO, Alessandra Cristina. (Orgs.) Educação brasileira: interfaces e solicitações recorrentes. Dourados: UFGD, 2011. 224 p.

REAL, Giselle Cristina Martins; MARRAN, Ana Lúcia; ZENI, Kelei. O Estado brasileiro em ação: delineamentos da política de revalidação de diplomas estrangeiros. In: REUNIÃO NACIONAL DA ANPED, 38., out. 2017, São Luís. Anais eletrônicos... Rio de Janeiro: Anped, 2017. Disponível em: <http://38reuniao.anped.org.br/sites/default/files/resources/programacao/trabalho_38anped_2017_ GT11_91.pdf>. Acesso em: 9 out. 2017.

REAL, Giselle Cristina Martins; OLIVEIRA, Verônica de Lourdes Pieto. A avaliação no contexto da política supranacional: efeitos na educação superior brasileira. In: CUNHA, Célio da; SOUSA, José Vieira de; SILVA, Maria Abádia da (Orgs.). Internacionalização da educação: discursos, práticas e reflexos sobre as políticas educativas. 1. ed. Belo Horizonte: Fino Traço, 2016. p. 223-242.

ROBLEDO, Rocio; CAILLÓN, Adriana. Procesos regionales en educación superior: el mecanismo de acreditación de carreras universitarias en el MERCOSUR. Reconocimiento regional de los títulos y de la calidad de la formación regional. Educación superior y sociedad, v. 14, n. 1, p. 73-98, 2009.

SCHMOELLER, Roseli et al. Mercosul Educativo na carreira de enfermagem. Rev. Bras. Enferm., Brasília, p. 856-861, set./out. 2012.

SERIKAWA, Leonardo Kazuo dos Santos. Acreditação e qualidade da educação superior: abrindo a caixa-preta do Sistema de Acreditação de Cursos Superiores do Mercosul. 2013. Dissertação (Mestrado em Desenvolvimento, Sociedade e Cooperação Internacional) - Universidade de Brasília, Brasília, 2013.

SOLANAS, Facundo. Analizar una política pública mercosuriana: el caso del ejercicio profesional y la acreditación universitaria regional. Revista SAAP, v. 8, n. 1, p. 43-64, mayo 2014.

SOUZA, Mary Ane de. Concepções de qualidade na educação superior: interseção entre os instrumentos de avaliação do Mercosul e do Brasil. 2016. Dissertação (Mestrado em Educação) Universidade Federal da Grande Dourados, Dourados, 2016.

STUBRIN, Adolfo. Los mecanismos nacionales de garantía pública de calidad en el marco de la internacionalización de la educación superior. Avaliação, Campinas, v. 10, n. 4, p. 9-22, 2005.

TEODORO, António. A educação em tempos de globalização neoliberal: os novos modos de regulação das políticas educacionais. Brasília: Liber Livro, 2011. 176 p. 
VERHINE, Robert Evan; FREITAS, Antônio Alberto da Silva Monteiro. A avaliação da educação superior: modalidades e tendências no cenário internacional. Revista Ensino Superior Unicamp, v. 3, n. 7, p. 16-39, 2012.

Submetido: 06/11/2018

Aprovado: 16/07/2019 